\title{
Colorectal cancer screening in Canada: results of a national survey
}

\author{
MJ Sewitch, PhD (1); C Fournier, MSc (2); A Ciampi, PhD (3); A Dyachenko, MSc (4)
}

\begin{abstract}
Canadian guidelines recommend colorectal-cancer (CRC) screening for individuals aged 50 to 74 years. The study objective was to estimate rates of CRC screening according to individual and geographical characteristics, and of adherence to current CRC screening guidelines. Respondents to the 2003 Canadian Community Health Survey Cycle 2.1 (aged $\geq 50$ years, without past or present CRC) participated. Fecal occult blood test (FOBT) and endoscopy utilization and screening rates were calculated. The sample included 16747 residents of Newfoundland, Ontario, Saskatchewan and British Columbia. Overall, the FOBT screening rate was $7.7 \%$ in the past year, and the endoscopy screening rate was $8.8 \%$ in the past 5 years. FOBT screening rates were higher in older and male respondents; endoscopy screening rates were higher in older respondents. Individuals aged 50 to 59 and over 90 years were least likely to have been screened. Approximately $70 \%$ of respondents were non-adherent to current CRC screening guidelines. Non-adherence rates were higher in most health regions of British Columbia. National survey data suggest CRC screening in Canada is low; younger persons and residents of British Columbia were least likely to report CRC screening.
\end{abstract}

Key words: colorectal cancer, screening, survey, FOBT, endoscopy

\section{Introduction}

In Canada, colorectal cancer (CRC) is the fourth most commonly diagnosed cancer and the second and third leading cause of cancer deaths in men and women, respectively. ${ }^{1}$ CRC screening reduces both CRC incidence through removal of premalignant polyps and CRC deaths through early detection and treatment. Since 1996, several organizations have published CRC screening guidelines for average-risk individuals, defined as those 50 years of age and older with average risk for the development of CRC. Canadian guidelines recommend fecal occult blood testing (FOBT) every 1 to 2 years $^{2-4}$ whereas the US guidelines recommend annual FOBT. ${ }^{5,6}$ For other screening modalities, similar periodicities are advocated by Canada and the US: every 10 years for colonoscopy and every 5 years for each of flexible sigmoidoscopy and double contrast barium enema, although the US guidelines also recommend a combination of annual FOBT with flexible sigmoidoscopy every 5 years.

Despite the widespread distribution of CRC screening guidelines, CRC screening is underutilized. In the US, several studies have employed national survey data and collected information through the use of either random-digit-dialing or in-person interviews. Research based on data from the National Health Interview Survey, ${ }^{7}$ the Behavioral Risk Factor Surveillance System, ${ }^{8}$ the Community Quality Index, ${ }^{9}$ the California Health Interview Survey ${ }^{10}$ and the Health Information National Trends Survey ${ }^{11}$ revealed that CRC screening rates vary from $15 \%$ to $65 \%$ depending on the time interval under study. In Ontario, research derived from either administrative or survey data estimates that less than $25 \%$ of the screen-eligible population has been screened. ${ }^{12-14}$ In Alberta, a populationbased survey revealed that only $14.3 \%$ of average-risk individuals were considered up-to-date with CRC screening. ${ }^{15}$

As CRC screening advances to the forefront of preventive health care through public and professional awareness, rates of CRC screening in Canada are of growing interest. However, the extent to which Canadians are screened for CRC according to guidelines remains unclear. Moreover, little is known about the characteristics of the individuals who undergo CRC screening and the use of CRC screening procedures over time. With the launching of several provincial CRC screening programs in Canada, understanding CRC screening disparities is pivotal to fostering effective planning, implementation and functioning of CRC screening endeavors. Thus, the purpose of this population-based study was to estimate rates of 1) FOBT and endoscopy as CRC screening procedures; and 2) adherence to current CRC screening guidelines.

\section{Methods}

\section{Data sources}

The main data source was the Statistics Canada Canadian Community Health Survey (CCHS) Cycle 2.1 (January to December 2003), ${ }^{16}$ which aimed to provide estimates of health determinants, health status and health system utilization in Canada. This survey included household residents aged 12 years and older in all provinces and territories. Residents living

Author References

1 Department of Medicine, McGill University, Montreal, QC

2 Division of Clinical Epidemiology, Research Institute of the McGill University Health Centre, Montreal, QC

3 Department of Epidemiology and Biostatistics, McGill University, Montreal, QC

4 Department of Epidemiology and Community Studies, St. Mary's Hospital Center, Montreal, QC

Correspondence: Maida J. Sewitch, PhD, 687 Pine Avenue West, V Building, The Royal Victoria Hospital, Montreal QC H3A 1A1, Tel.: 514-934-1934 local 44736, Fax.: 514-934-8293, Email: maida.sewitch@mcgill.ca 
on Indian Reserves or in remote areas, and full-time members of the Canadian Armed Forces were excluded. The CCHS Cycle 2.1 survey contained basic socio-demographic information on all respondents in all health regions. However, the CRC screening module was administered at the discretion of health regions. Respondents to the CRC screening module were from all health regions of Newfoundland and British Columbia, and from 14 of 37 and 7 of 11 health regions of Ontario and Saskatchewan, respectively. ${ }^{17}$ Health regions are defined by provincial health ministries and generally comprise legislated administrative areas representing geographic areas of responsibility for hospital boards or regional health authorities. ${ }^{18}$ Survey data are non-nominative; respondents were not identified.

\section{Study population}

The study population included survey respondents who completed the CRC screening module and reported being 50 years of age and older and without past or present CRC. Respondents failing to provide information on when both FOBT and endoscopy were last performed were excluded. Sociodemographic characteristics included age, sex, highest level of education achieved and household income. Clinical characteristics included bowel disease (having received a diagnosis of either Crohn's disease or ulcerative colitis from a health care professional). Geographical characteristics included residential area (urban vs. rural), health region and province of residence.

\section{Outcome variables}

FOBT and endoscopy (defined as sigmoidoscopy or colonoscopy) screening and utilization rates were based on questionnaire responses that assessed when the procedure was last performed and the indication for the procedure (screening, non-screening). Screening rates were derived from screening procedures, which were defined as those performed for "regular check-up", "age”, "race”, or "family history of CRC". The degree of an affected family member was not assessed. Utilization rates were derived from screening and non-screening procedures, which were defined as those performed for "follow-up of previous problem" or "other reason". FOBT can be used in a nonscreening context, for example, to detect the presence of blood in the stool of a patient with anemia. Three adherence rates were defined according to CRC screening guideline-recommended periodicities in place at the time of the study. (1) Adherence to FOBT screening guidelines was defined as having an FOBT in the past 2 years; (2) Adherence to endoscopy screening guidelines was defined as having an endoscopy in the past 10 years; (3) Adherence to current CRC screening guidelines was defined as either (1) or (2). The three adherence rates, which were based on procedures performed for all indications, provide an estimate of the number of respondents considered up-to-date with CRC screening. The underlying assumption is that once the procedure is performed, repeat testing for screening purposes should follow guideline-recommended periodicities.

\section{Statistical analysis}

Descriptive statistics were used to characterize the study population overall and according to screening modality. Screening rates were calculated as the number of respondents reporting a screening procedure, divided by the number of respondents reporting a screening procedure plus those reporting never undergoing the procedure, according to the timing of the last screening procedure. Respondents who underwent the procedure for non-screening purposes were excluded. Utilization rates were calculated as the number of respondents reporting either a screening or nonscreening procedure divided by the total number of respondents in the study population, according to the timing of the last procedure. FOBT rates were calculated according to the following 5 time intervals: less than 1 year ago, 1 to 2 years ago, 2 to 3 years ago, more than 3 years ago and never. Endoscopy rates were calculated according to the following 4 time intervals: within the last 5 years, 6 to 10 years ago, more than 10 years ago and never. These time intervals differ from the guidelinerecommended periodicities to allow for comparisons over time. Overall screening and utilization rates were computed for the entire study population. Screening rates were also computed by sex, age group, household income level, education level, bowel disease status and geographical areas (residential area, health region and province of residence).

Rates were computed by aggregating weighted data over the participating health regions. Rates may not be representative of the entire province when only some health regions are sampled. Thus, only regional screening rates were reported for Ontario and Saskatchewan. By comparison, regional and provincial screening rates were reported for Newfoundland and British Columbia, where all health regions were sampled. Rates for the 3 adherence outcomes were calculated overall and according to health regions. Although rates of adherence to current CRC screening guidelines were based on FOBT and endoscopy utilization, respondents having valid information on only one procedure were included and classified accordingly. Bootstrap weights provided by Statistics Canada were employed to compute a $95 \%$ confidence interval ( $95 \% \mathrm{CI})$ using the BOOTVARE_V30 program (Version 3.0). ${ }^{19}$ All analyses were performed using SAS statistical software. ${ }^{20}$

The sizes of both the Canadian population at survey time and the study population (i.e. number of Canadians represented by the respondents) were estimated using the weighted design previously mentioned. All figures presented are weighted values, in keeping with the policies of Statistics Canada.

\section{Results}

\section{Study population}

The CRC screening module was administered to 39178 individuals (Figure 1). Of these, 16747 respondents met eligibility criteria and were estimated to represent 2394124 Canadians (according to weighting procedures). The size of the Canadian population aged 12 and over was estimated at 26578 128. Of the eligible respondents, 16545 and 16648 provided information on utilization of FOBT and endoscopy, respectively; 14482 and 13949 provided information on FOBT and endoscopy screening, respectively. 
Table 1 presents the socio-demographic, clinical and geographical characteristics of the study population overall and according to screening modality. Overall, more of the respondents were female, aged 50 to 64, post high-school graduates, born in Canada, white, not employed, without bowel disease, living in urban areas and from British Columbia. Of the 14482 respondents with FOBT screening information, $21.6 \%$ underwent FOBT screening in their lifetimes. Compared to the total study population, a greater percentage of those reporting FOBT screening were aged 50 to 64 and were not employed outside the home. Of the 13949 respondents with endoscopy screening information, $11.3 \%$ underwent endoscopy screening in their lifetimes. Compared to the total study population, a greater percentage of those reporting endoscopy screening were not employed outside the home and were residents of Ontario; a smaller percentage were residents of British Columbia.

\section{FOBT screening rates}

Table 2 presents FOBT screening rates by time interval, according to sociodemographic, clinical and geographical characteristics. Overall FOBT screening rates were $7.7 \%$ in the past year, $5.1 \% 1$ to 2 years ago, $2.5 \% 2$ to 3 years ago, and $6.3 \%$ over 3 years ago; $78.4 \%$ never had a screening FOBT. FOBT screening rates in the past year and 1 to 2 years ago were higher in males, those with bowel disease and those aged 65 years and older; rates were lowest among the 50 to 59 year age group. No rural vs. urban difference was observed. Provincial FOBT screening rates were higher in residents of British Columbia compared to Newfoundland. Health regional FOBT screening varied within each province (Table 3). Across the 43 health regions of all provinces, FOBT screening rates in the past year ranged from $2.4 \%$ to $21.5 \%$ and rates of never undergoing FOBT screening ranged from $54.3 \%$ to $89.2 \%$. In comparison, overall FOBT utilization rates were: $9.1 \%$ in the past year, $6.0 \% 1$ to 2 years ago, $11.8 \%$ over 3 years ago; $69.3 \%$ never had an FOBT (data not shown).

\section{Endoscopy screening rates}

Table 4 presents endoscopy screening rates by time interval, according to sociodemographic, clinical and geographical characteristics. Overall endoscopy screening rates were $8.8 \%$ in the past 5 years and $1.5 \%$ in the past 6 to 10 years; $88.7 \%$ never had a screening endoscopy. Endoscopy screening rates in the past 5 years were higher in respondents with bowel disease and those aged 65 years and older; rates were lowest among the 50 to 59 year and 90 to 100 year age groups. No rural vs. urban difference was observed. Provincial endoscopy screening rates were higher in residents of Newfoundland compared to British Columbia. Health regional endoscopy screening rates varied within each province (Table 3). Across the 43 health regions (i.e. all provinces), endoscopy screening rates in the past 5 years ranged from $4.2 \%$ to
$16.5 \%$, and rates of never undergoing endoscopy screening ranged from $81.1 \%$ to $94.3 \%$. In comparison, overall endoscopy utilization rates were $16.7 \%$ in the past 5 years and $3.9 \%$ in the past 6 to 10 years; $75.6 \%$ never had an endoscopy (data not shown).

\section{Adherence to FOBT screening guidelines}

Table 5 shows that $15.1 \%$ of respondents were adherent to FOBT screening guidelines. Figure 2 shows that rates of adherence to FOBT screening guidelines were highest in the southern health regions of British Columbia and some health regions of Saskatchewan and Ontario. Rates of neveruse of FOBT across all health regions (Figure 3) were highest in eastern health regions of British Columbia, the Saskatoon region, northeastern Ontario and parts of Newfoundland.

FIGURE 1

Study population selection from the CCHS Cycle 2.1 CRC screening module respondents

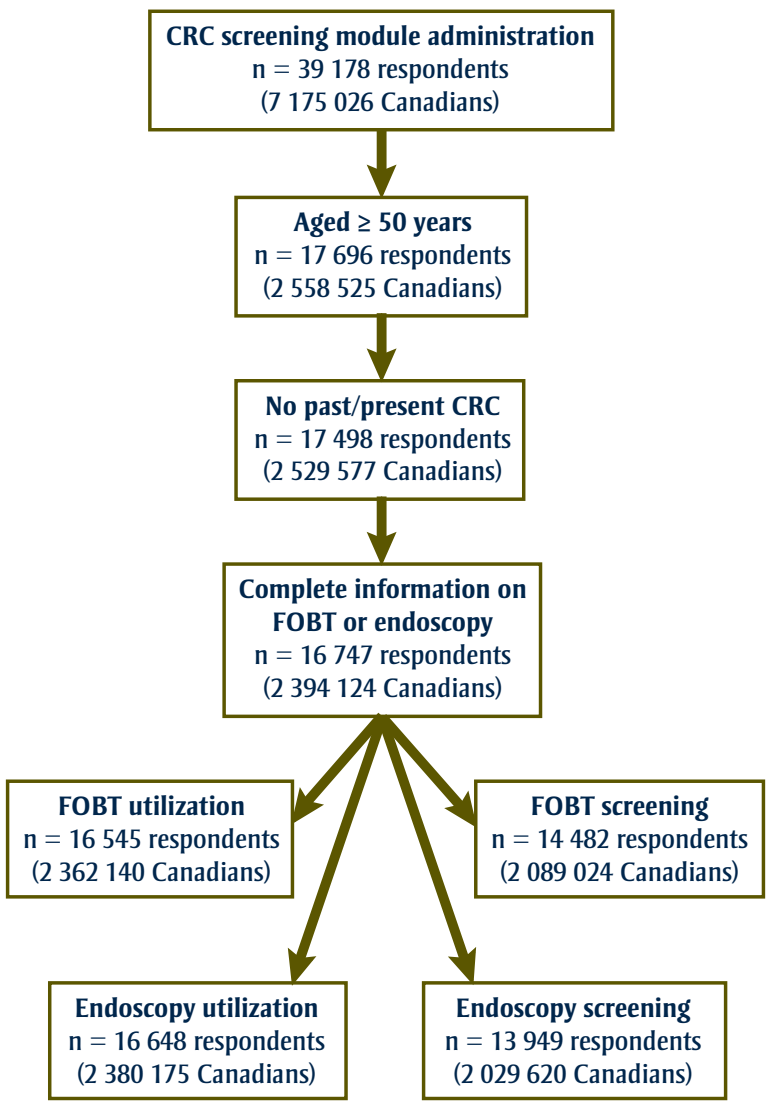


TABLE 1

Socio-demographic, clinical and geographical characteristics of the study population according to FOBT and endoscopy screening status

\begin{tabular}{|c|c|c|c|c|c|c|c|}
\hline \multirow[t]{2}{*}{ Characteristic } & \multirow[t]{2}{*}{ Category } & \multirow{2}{*}{$\begin{array}{c}\text { Overall } \\
\text { n (2 } 394 \text { 124) }\end{array}$} & \multicolumn{3}{|c|}{ FOBT screening ${ }^{a}$} & \multicolumn{2}{|c|}{ Endoscopy ${ }^{b}$ screening } \\
\hline & & & $\%^{c}$ & n (451 669) & $\%^{c}$ & n (229 578) & $\%^{c}$ \\
\hline \multicolumn{8}{|l|}{ Socio-demographic } \\
\hline \multirow[t]{2}{*}{ Sex } & male & 1140566 & 47.6 & 233372 & 51.7 & 112541 & 49.0 \\
\hline & female & 1253559 & 52.4 & 218298 & 48.3 & 117037 & 51.0 \\
\hline \multirow[t]{2}{*}{ Age } & 50 to 64 & 1429679 & 59.7 & 222473 & 49.3 & 122450 & 53.3 \\
\hline & $65+$ & 964446 & 40.3 & 229197 & 50.7 & 107128 & 46.7 \\
\hline \multirow[t]{4}{*}{ Education } & $<$ high school & 630647 & 27.0 & 110676 & 25.1 & 56249 & 25.0 \\
\hline & high school grad. & 462201 & 19.8 & 89306 & 20.3 & 42533 & 18.9 \\
\hline & post high school & 143139 & 6.1 & 23708 & 5.4 & 17793 & 7.9 \\
\hline & post high school grad. & 1095953 & 47.0 & 216554 & 49.2 & 108544 & 48.2 \\
\hline \multirow[t]{2}{*}{ Country of birth } & Canada & 1653452 & 70.3 & 315685 & 70.9 & 171337 & 75.5 \\
\hline & other & 697280 & 29.7 & 129554 & 29.1 & 55543 & 24.5 \\
\hline \multirow[t]{2}{*}{ Cultural/racial origin } & white & 2067992 & 88.0 & 405037 & 91.1 & 205344 & 90.8 \\
\hline & other & 281342 & 12.0 & 39630 & 8.9 & 20748 & 9.2 \\
\hline \multirow[t]{3}{*}{ Household income } & low to low medium & 656704 & 33.2 & 116925 & 31.1 & 64074 & 33.7 \\
\hline & upper medium & 685018 & 34.7 & 132543 & 35.2 & 64003 & 33.6 \\
\hline & high & 635229 & 32.1 & 126742 & 33.7 & 62152 & 32.7 \\
\hline \multirow{3}{*}{$\begin{array}{l}\text { Employment status } \\
\text { (over past year) }\end{array}$} & full-time & 864382 & 37.0 & 126254 & 28.6 & 68193 & 30.2 \\
\hline & part-time & 211809 & 9.1 & 39937 & 9.0 & 21600 & 9.6 \\
\hline & no job & 1258634 & 53.9 & 275747 & 62.4 & 135673 & 60.2 \\
\hline \multicolumn{8}{|l|}{ Clinical } \\
\hline \multirow[t]{2}{*}{ Bowel disease } & yes & 86080 & 3.6 & 16664 & 3.7 & 10699 & 4.7 \\
\hline & no & 2305488 & 96.4 & 434428 & 96.3 & 218770 & 95.3 \\
\hline \multicolumn{8}{|l|}{ Geographical } \\
\hline \multirow[t]{2}{*}{ Residential area } & urban & 1895462 & 79.2 & 355944 & 78.8 & 183465 & 79.9 \\
\hline & rural & 498663 & 20.8 & 95725 & 21.2 & 46114 & 20.1 \\
\hline \multirow[t]{4}{*}{ Residential province } & $\begin{array}{l}\text { Newfoundland \& } \\
\text { Labrador }\end{array}$ & 155166 & 6.5 & 19859 & 4.4 & 15673 & 6.8 \\
\hline & Ontario & 889608 & 37.2 & 171566 & 38.0 & 111762 & 48.7 \\
\hline & Saskatchewan & 168279 & 7.0 & 31603 & 7.0 & 15508 & 6.8 \\
\hline & British Columbia & 1181072 & 49.3 & 228641 & 50.6 & 86636 & 37.7 \\
\hline
\end{tabular}

All numbers are weighted

Numbers may not be equal to the population $\mathrm{n}$ due to missing data

${ }^{a}$ Respondents reporting lifetime FOBT screening

${ }^{\mathrm{b}}$ Respondents reporting lifetime endoscopy screening

' Based on valid responses (excludes missing values) 
TABLE 2

FOBT screening rates by time interval according to socio-demographic, clinical and geographical characteristics $\left(\mathbf{n}^{\mathrm{a}}=14482\right)$

\begin{tabular}{|c|c|c|c|c|c|c|c|c|c|c|c|c|c|c|c|}
\hline \multirow{4}{*}{$\begin{array}{l}\text { Characteristic } \\
\text { OVERALL }\end{array}$} & \multicolumn{15}{|c|}{ Last reported FOBT screening } \\
\hline & \multirow{3}{*}{$\begin{array}{r}<1 \text { ye } \\
\text { Rate } \\
7.7\end{array}$} & \multirow{2}{*}{\multicolumn{2}{|c|}{$95 \% \mathrm{Cl}$}} & \multicolumn{3}{|c|}{1 to 2 years } & \multicolumn{3}{|c|}{2 to 3 years } & \multicolumn{3}{|c|}{$3+$ years } & \multirow{2}{*}{\multicolumn{3}{|c|}{$\begin{array}{l}\text { never } \\
\text { Rate } \quad 95 \% \mathrm{Cl}\end{array}$}} \\
\hline & & & & \multirow{2}{*}{$\begin{array}{r}\text { Rate } \\
5.1\end{array}$} & \multicolumn{2}{|c|}{$95 \% \mathrm{CI}$} & \multirow{2}{*}{$\begin{array}{r}\text { Rate } \\
2.5\end{array}$} & \multicolumn{2}{|c|}{$95 \% \mathrm{Cl}$} & \multirow{2}{*}{$\begin{array}{r}\text { Rate } \\
6.3\end{array}$} & \multicolumn{2}{|c|}{$95 \% \mathrm{Cl}$} & & & \\
\hline & & 7.1 & 8.4 & & 4.6 & 5.6 & & 2.2 & 2.8 & & 5.8 & 6.9 & 78.4 & 77.5 & 79.3 \\
\hline \multicolumn{16}{|l|}{ Sex } \\
\hline male & 9.3 & 8.2 & 10.3 & 5.8 & 5.0 & 6.6 & 2.3 & 1.8 & 2.7 & 5.7 & 5.0 & 6.5 & 76.9 & 75.5 & 78.4 \\
\hline female & 6.2 & 5.5 & 7.0 & 4.4 & 3.8 & 5.0 & 2.7 & 2.3 & 3.2 & 6.9 & 6.2 & 7.6 & 79.7 & 78.6 & 80.9 \\
\hline \multicolumn{16}{|l|}{ Age (years) } \\
\hline 50 to 64 & 6.6 & 5.7 & 7.4 & 4.5 & 3.8 & 5.1 & 1.8 & 1.5 & 2.2 & 4.8 & 4.1 & 5.4 & 82.4 & 81.2 & 83.6 \\
\hline $65+$ & 9.5 & 8.4 & 10.6 & 6.0 & 5.3 & 6.8 & 3.5 & 3.0 & 4.1 & 8.7 & 7.9 & 9.6 & 72.2 & 70.7 & 73.7 \\
\hline 50 to 59 & 5.7 & 4.8 & 6.6 & 3.8 & 3.2 & 4.5 & 1.7 & 1.2 & 2.2 & 4.2 & 3.5 & 4.9 & 84.5 & 83.2 & 85.9 \\
\hline 60 to 69 & 9.3 & 8.1 & 10.5 & 5.9 & 4.9 & 6.9 & 2.7 & 2.1 & 3.3 & 6.5 & 5.4 & 7.6 & 75.6 & 73.8 & 77.4 \\
\hline 70 to 79 & 10.3 & 8.8 & 11.8 & 6.5 & 5.4 & 7.7 & 3.7 & 2.8 & 4.5 & 9.0 & 7.7 & 10.2 & 70.6 & 68.4 & 72.8 \\
\hline 80 to 89 & 7.7 & 4.7 & 10.6 & 6.2 & 4.5 & 8.0 & 3.8 & 2.7 & 5.0 & 11.8 & 9.5 & 14.2 & 70.5 & 66.8 & 74.1 \\
\hline 90 to 100 & $\mathrm{n} / \mathrm{a}$ & n/a & $n / a$ & 3.7 & 0.6 & 6.8 & $\mathrm{n} / \mathrm{a}$ & n/a & n/a & 10.5 & $\mathrm{n} / \mathrm{a}$ & 21.5 & 83.0 & 72.0 & 93.9 \\
\hline \multicolumn{16}{|l|}{ Residential area } \\
\hline urban & 7.7 & 6.9 & 8.4 & 4.9 & 4.4 & 5.4 & 2.6 & 2.2 & 3.0 & 6.4 & 5.8 & 7.0 & 78.5 & 77.4 & 79.5 \\
\hline rural & 7.9 & 6.7 & 9.2 & 5.8 & 4.7 & 6.8 & 2.0 & 1.5 & 2.6 & 6.3 & 5.3 & 7.3 & 78.0 & 76.1 & 79.8 \\
\hline \multicolumn{16}{|l|}{ Education } \\
\hline$<$ high school & 6.9 & 5.9 & 8.0 & 4.8 & 4.0 & 5.7 & 2.5 & 2.0 & 3.1 & 6.3 & 5.3 & 7.2 & 79.5 & 77.8 & 81.1 \\
\hline high school grad. & 7.7 & 6.1 & 9.3 & 5.6 & 4.5 & 6.7 & 2.7 & 1.9 & 3.4 & 5.7 & 4.7 & 6.6 & 78.4 & 76.3 & 80.6 \\
\hline post high school & 9.1 & 6.4 & 11.9 & 3.7 & 1.8 & 5.6 & 1.9 & 1.0 & 2.9 & 5.2 & 3.1 & 7.2 & 80.1 & 75.8 & 84.4 \\
\hline $\begin{array}{l}\text { post high school } \\
\text { graduate }\end{array}$ & 8.0 & 7.0 & 9.0 & 5.1 & 4.4 & 5.8 & 2.5 & 2.0 & 3.0 & 6.9 & 6.0 & 7.7 & 77.5 & 76.1 & 79.0 \\
\hline \multicolumn{16}{|l|}{ Household income } \\
\hline low to low medium & 6.8 & 5.6 & 7.9 & 4.4 & 3.7 & 5.1 & 2.6 & 2.0 & 3.2 & 7.1 & 6.1 & 8.2 & 79.1 & 77.5 & 80.8 \\
\hline upper medium & 7.9 & 6.8 & 9.1 & 4.9 & 4.1 & 5.7 & 2.1 & 1.6 & 2.6 & 7.3 & 6.3 & 8.3 & 77.8 & 76.1 & 79.5 \\
\hline high & 9.0 & 7.5 & 10.5 & 5.7 & 4.7 & 6.8 & 2.8 & 2.0 & 3.5 & 5.0 & 4.0 & 5.9 & 77.6 & 75.4 & 79.7 \\
\hline \multicolumn{16}{|l|}{ Bowel disease } \\
\hline yes & 11.9 & 7.8 & 15.9 & 5.5 & 2.8 & 8.2 & 3.0 & 1.2 & 4.8 & 10.1 & 6.5 & 13.8 & 69.5 & 63.8 & 75.1 \\
\hline no & 7.6 & 6.9 & 8.2 & 5.1 & 4.5 & 5.6 & 2.5 & 2.2 & 2.8 & 6.2 & 5.7 & 6.8 & 78.6 & 77.7 & 79.6 \\
\hline \multicolumn{16}{|l|}{ Residential province ${ }^{c}$} \\
\hline $\begin{array}{l}\text { Newfoundland } \\
\text { \&Labrador }\end{array}$ & 3.8 & 2.7 & 4.9 & 2.8 & 1.7 & 3.8 & 2.0 & 0.8 & 3.1 & 6.1 & 4.6 & 7.7 & 85.4 & 83.2 & 87.5 \\
\hline British Columbia & 8.1 & 7.0 & 9.2 & 5.1 & 4.3 & 5.9 & 2.1 & 1.7 & 2.5 & 6.4 & 5.6 & 7.3 & 78.4 & 76.8 & 79.9 \\
\hline
\end{tabular}

Rate percentages represent weighted data

a Number of respondents providing information on FOBT screening and representing 2089024 Canadians

${ }^{\mathrm{b}}$ Respondents categorized according to the last reported date of screening FOBT

FOBT performed for non-screening purposes are excluded

c Ontario and Saskatchewan provincial rates are not reported because data are not available for all health regions

$\mathrm{n} / \mathrm{a}=$ not available because non-weighted data cells contained less than 5 individuals (Statistics Canada privacy protection regulation) 
TABLE 3

Summary of health regional screening rates of FOBT and endoscopy by province

\begin{tabular}{|c|c|c|c|c|c|}
\hline \multirow[t]{2}{*}{ Province } & \multirow{2}{*}{$\begin{array}{l}\text { Health regions } \\
\text { n (\%) }\end{array}$} & \multicolumn{2}{|c|}{$\begin{array}{l}\text { FOBT } \\
\text { range }^{b}\end{array}$} & \multicolumn{2}{|c|}{$\begin{array}{l}\text { Endoscopy } \\
\text { range }^{b}\end{array}$} \\
\hline & & past year & never & past 5 years & never \\
\hline Overalla $^{a}$ & 43 & 2.4 to 21.5 & 54.3 to 89.2 & 4.2 to 16.5 & 81.1 to 94.3 \\
\hline $\begin{array}{l}\text { Newfoundland } \\
\text { \& Labrador }\end{array}$ & $6(100 \%)$ & 2.8 to 5.4 & 83.6 to 89.1 & 4.8 to 12.0 & 84.6 to 94.3 \\
\hline Ontario & $14(37.8 \%)$ & 3.9 to 13.1 & 62.5 to 85.3 & 8.2 to 16.5 & 81.1 to 88.4 \\
\hline Saskachewan & $7(63.6 \%)$ & 3.8 to 21.5 & 54.3 to 85.5 & 7.5 to 10.8 & 82.6 to 90.8 \\
\hline British Columbia & $16(100 \%)$ & 2.4 to 15.1 & 56.5 to 89.2 & 4.2 to 13.4 & 83.4 to 93.8 \\
\hline
\end{tabular}

${ }^{a}$ All health regions/provinces combined

${ }^{\mathrm{b}}$ Range values are percentages

\section{Adherence to endoscopy screening guidelines}

A total of $20.6 \%$ of respondents were adherent to endoscopy screening guidelines (Table 5). Figure 4 shows that health regional rates of adherence to endoscopy screening guidelines were highest in southeastern British Columbia, southern Alberta, northern Ontario and parts of Newfoundland. Rates of never-use of endoscopy (Figure 5) were highest in British Columbia and parts of Newfoundland. No clear geographical pattern emerged for Saskatchewan, as less than half of provincial health regions were sampled.

\section{Adherence to current CRC screening guidelines}

In this study population, $30.1 \%$ of respondents were adherent and 69.9\% were non-adherent to current CRC screening guidelines (Table 5). Figure 6 shows that non-adherence rates were highest in most health regions of British Columbia and lowest in many health regions of Ontario. Non-adherence rates for Newfoundland and Saskatchewan varied by health region.

\section{Discussion}

The overarching goal of this Canadian population-based study was to increase our knowledge of the extent to which Canadians
50 years of age and older undergo CRC screening. Our results indicate that rates of CRC screening by FOBT and endoscopy were low and subject to considerable geographic variation. Provincial screening rates (Newfoundland and British Columbia) revealed that up to $85.4 \%$ and $91.4 \%$ of residents had never been screened with FOBT and endoscopy, respectively. Health regional screening rates (Saskatchewan and Ontario) were also low, with up to $85.5 \%$ and $90.8 \%$ of the population having never been screened with FOBT and endoscopy, respectively. The large geographical variation echoes findings from one Albertabased study ${ }^{21}$ and several US studies that show large regional and state level differences in CRC test use. ${ }^{22,23}$ Geographical variation in use of health preventive services is evident for other types of screening in Canada. Health regional rates of the Papanicolaou (Pap) test in Ontario reportedly vary from $12 \%$ to $74 \%,{ }^{24}$ while across Canada provincial rates vary between $70 \%$ to $88 \% .{ }^{25}$ Similarly, survey data indicate that Canadian provincial breast cancer screening rates vary from approximately $9 \%$ in Nunavut to $67 \%$ in New Brunswick. ${ }^{25}$

CRC screening rates varied by age as well. People 65 years of age and older were screened more often by both FOBT and endoscopy compared to their younger counterparts, similar to the findings of others. ${ }^{26-34}$ Individuals aged 50 to 59 were less likely to report CRC screening, suggesting a delayed uptake of CRC screening recommendations by either or both physicians and younger patients, since at the time of the survey no CRC screening programs were in place. Furthermore, FOBT and endoscopy screening declined in the 80 to 89 year age group and, for endoscopy, dropped off dramatically in the 90 to 100 year age group. These findings may reflect the cost-effective model proposed for the Canadian population, which recommends to stop screening at age $74 .^{3,35}$

No meaningful differences were found in CRC screening rates according to urban vs. rural residence, suggesting that variation in screening was not due to availability of health care resources. One might have expected that rural areas would have been disadvantaged in terms of accessibility to sigmoidoscopy and colonoscopy and, consequently, more likely to have employed FOBT, which is readily available. Our finding corroborates that reported by another Canadian similar study that found CRC procedure rates in rural and urban areas. ${ }^{21}$ One possible explanation for the lack of variability between residential areas may rest in regional similarities in physician practice style. Since both FOBT and endoscopy are considered primary screening modalities, physicians who adhere to endoscopy screening may recommend endoscopy regardless of whether facilities are located outside of the patient's residential area.

Rates of FOBT increased moderately between 1 to 2 years ago and the past year, while rates of endoscopy increased almost 6-fold in the past decade. Not only do these trends indicate a steady rise in CRC screening, they may also depict a shift from FOBT to endoscopy for primary CRC screening. . $^{21,34,36-39}$ These findings should alert decision- and policy-makers of an impending increased demand for screening endoscopy, since at the present time there are insufficient resources to meet that demand..$^{35}$ 
TABLE 4

Endoscopy screening rates by time interval according to socio-demographic, clinical and geographical characteristics $\left(\mathbf{n}^{\mathrm{a}}=13949\right)$

\begin{tabular}{|c|c|c|c|c|c|c|c|c|c|c|c|c|}
\hline \multirow{4}{*}{$\begin{array}{l}\text { Characteristic } \\
\text { OVERALL }\end{array}$} & \multicolumn{12}{|c|}{ Last reported endoscopy screening ${ }^{b}$} \\
\hline & \multicolumn{3}{|c|}{0 to 5 years } & \multicolumn{3}{|c|}{6 to 10 years } & \multicolumn{3}{|c|}{$10+$ years } & \multicolumn{3}{|l|}{ never } \\
\hline & \multirow{2}{*}{$\begin{array}{c}\text { Rate } \\
8.8\end{array}$} & \multicolumn{2}{|c|}{$95 \% \mathrm{Cl}$} & \multirow{2}{*}{$\begin{array}{c}\text { Rate } \\
1.5\end{array}$} & \multicolumn{2}{|c|}{$95 \% \mathrm{Cl}$} & \multirow{2}{*}{$\begin{array}{c}\text { Rate } \\
1.0\end{array}$} & \multicolumn{2}{|c|}{$95 \% \mathrm{Cl}$} & \multirow{2}{*}{$\begin{array}{l}\text { Rate } \\
88.7\end{array}$} & \multicolumn{2}{|c|}{$95 \% \mathrm{Cl}$} \\
\hline & & 8.2 & 9.5 & & 1.2 & 1.8 & & 0.8 & 1.2 & & 88.0 & 89.4 \\
\hline \multicolumn{13}{|l|}{ Sex } \\
\hline male & 9.0 & 8.0 & 10.0 & 1.3 & 0.9 & 1.7 & 1.1 & 0.7 & 1.5 & 88.7 & 87.6 & 89.7 \\
\hline female & 8.7 & 7.8 & 9.6 & 1.7 & 1.3 & 2.1 & 0.9 & 0.7 & 1.2 & 88.7 & 87.7 & 89.7 \\
\hline \multicolumn{13}{|l|}{ Age (years) } \\
\hline 50 to 64 & 8.1 & 7.3 & 9.0 & 1.1 & 0.8 & 1.5 & 0.6 & 0.4 & 0.9 & 90.1 & 89.2 & 91.0 \\
\hline $65+$ & 10.0 & 8.9 & 11.0 & 2.0 & 1.6 & 2.5 & 1.6 & 1.2 & 2.0 & 86.5 & 85.3 & 87.6 \\
\hline 50 to 59 & 7.3 & 6.4 & 8.3 & 1.0 & 0.7 & 1.4 & 0.5 & 0.3 & 0.8 & 91.1 & 90.1 & 92.2 \\
\hline 60 to 69 & 10.4 & 9.2 & 11.6 & 1.8 & 1.2 & 2.4 & 1.0 & 0.6 & 1.4 & 86.9 & 85.6 & 88.2 \\
\hline 70 to 79 & 10.3 & 8.8 & 11.8 & 2.1 & 1.6 & 2.7 & 1.7 & 0.9 & 2.4 & 86.0 & 84.3 & 87.7 \\
\hline 80 to 89 & 9.7 & 6.6 & 12.8 & 1.6 & 0.7 & 2.5 & 2.1 & 1.3 & 3.0 & 86.6 & 83.4 & 89.8 \\
\hline 90 to 100 & 2.7 & $n / a$ & 5.7 & $\mathrm{n} / \mathrm{a}$ & $\mathrm{n} / \mathrm{a}$ & $\mathrm{n} / \mathrm{a}$ & $\mathrm{n} / \mathrm{a}$ & $\mathrm{n} / \mathrm{a}$ & $\mathrm{n} / \mathrm{a}$ & 94.6 & 90.5 & 98.8 \\
\hline \multicolumn{13}{|l|}{ Residential area } \\
\hline urban & 9.0 & 8.2 & 9.8 & 1.5 & 1.2 & 1.8 & 0.9 & 0.7 & 1.1 & 88.6 & 87.7 & 89.4 \\
\hline rural & 8.2 & 7.1 & 9.4 & 1.4 & 0.9 & 1.9 & 1.2 & 0.6 & 1.9 & 89.1 & 87.8 & 90.4 \\
\hline \multicolumn{13}{|l|}{ Education } \\
\hline$<$ high school & 8.2 & 7.1 & 9.2 & 1.6 & 1.1 & 2.0 & 1.0 & 0.6 & 1.4 & 89.3 & 88.1 & 90.6 \\
\hline high school grad. & 8.4 & 6.8 & 10.0 & 1.3 & 0.7 & 1.9 & 1.0 & 0.5 & 1.4 & 89.3 & 87.6 & 91.1 \\
\hline post high school & 10.8 & 7.6 & 13.9 & 2.6 & 0.5 & 4.7 & 1.7 & $\mathrm{n} / \mathrm{a}$ & 3.7 & 84.9 & 81.3 & 88.6 \\
\hline post high school grad. & 9.3 & 8.2 & 10.4 & 1.4 & 1.0 & 1.8 & 0.9 & 0.7 & 1.2 & 88.4 & 87.2 & 89.5 \\
\hline \multicolumn{13}{|l|}{ Household income } \\
\hline low to low medium & 8.8 & 7.5 & 10.2 & 1.6 & 1.1 & 2.0 & 1.2 & 0.8 & 1.7 & 88.4 & 87.0 & 89.8 \\
\hline upper medium & 8.5 & 7.4 & 9.6 & 1.7 & 1.2 & 2.1 & 1.1 & 0.6 & 1.6 & 88.7 & 87.5 & 90.0 \\
\hline high & 9.1 & 7.7 & 10.4 & 1.5 & 0.8 & 2.2 & 0.7 & 0.4 & 1.0 & 88.7 & 87.2 & 90.2 \\
\hline \multicolumn{13}{|l|}{ Bowel disease } \\
\hline yes & 23.2 & 16.5 & 29.9 & 4.1 & 1.6 & 6.6 & $\mathrm{n} / \mathrm{a}$ & $\mathrm{n} / \mathrm{a}$ & $\mathrm{n} / \mathrm{a}$ & 71.0 & 63.7 & 78.2 \\
\hline no & 8.6 & 7.9 & 9.2 & 1.4 & 1.2 & 1.7 & 1.0 & 0.8 & 1.2 & 89.0 & 88.3 & 89.7 \\
\hline \multicolumn{13}{|l|}{ Residential province $^{c}$} \\
\hline $\begin{array}{l}\text { Newfoundland } \\
\text { \& Labrador }\end{array}$ & 9.0 & 7.3 & 10.8 & 1.7 & 0.7 & 2.7 & 1.2 & 0.5 & 2.0 & 88.1 & 86.1 & 90.0 \\
\hline British Columbia & 6.5 & 5.7 & 7.4 & 1.2 & 0.8 & 1.6 & 0.8 & 0.5 & 1.2 & 91.4 & 90.5 & 92.4 \\
\hline
\end{tabular}

Percentages represent weighted data

${ }^{a}$ Number of respondents providing information on endoscopy screening and representing 2029620 Canadians

Rates are based on valid responses (excludes missing values)

${ }^{\mathrm{b}}$ Respondents categorized according to the last reported date of screening endoscopy (sigmoidoscopy or colonoscopy)

Endoscopies performed for non-screening purposes are excluded

${ }^{c}$ Ontario and Saskatchewan provincial rates are not reported because data are not available for all health regions

$\mathrm{n} / \mathrm{a}=$ not available because non-weighted data cells contained less than 5 individuals (Statistics Canada privacy protection regulation) 
TABLE 5

Frequency of the three adherence outcomes

\begin{tabular}{|c|c|c|}
\hline Outcome & $\mathbf{n}$ & $\%^{\mathrm{a}}$ \\
\hline \multicolumn{3}{|c|}{ Adherence to FOBT screening guidelines ${ }^{b}$} \\
\hline yes & 356535 & 15.1 \\
\hline no & 2005605 & 84.9 \\
\hline \multicolumn{3}{|c|}{ Adherence to endoscopy screening guidelines ${ }^{c}$} \\
\hline yes & 490128 & 20.6 \\
\hline no & 1890047 & 79.4 \\
\hline \multicolumn{3}{|c|}{ Adherence to current CRC screening guidelines ${ }^{d}$} \\
\hline yes & 720899 & 30.1 \\
\hline $\mathrm{no}^{\mathrm{e}}$ & 1673225 & 69.9 \\
\hline
\end{tabular}

All numbers are weighted

Includes procedures for all indications

${ }^{a}$ Based on valid responses (excludes missing values)

${ }^{\mathrm{b}}$ Reported use in the past 2 years for 16545 respondents ( $1.3 \%$ missing values)

c Reported use in the past 10 years for 16648 respondents ( $0.6 \%$ missing values)

${ }^{d}$ Reported use of FOBT in the past 2 years or endoscopy in the past 10 years for 16747 respondents

${ }^{\mathrm{e}}$ Includes $1.3 \%$ of respondents classified according to only one procedure

FIGURE 2.

Health regional rates of adherence to FOBT screening guidelines*

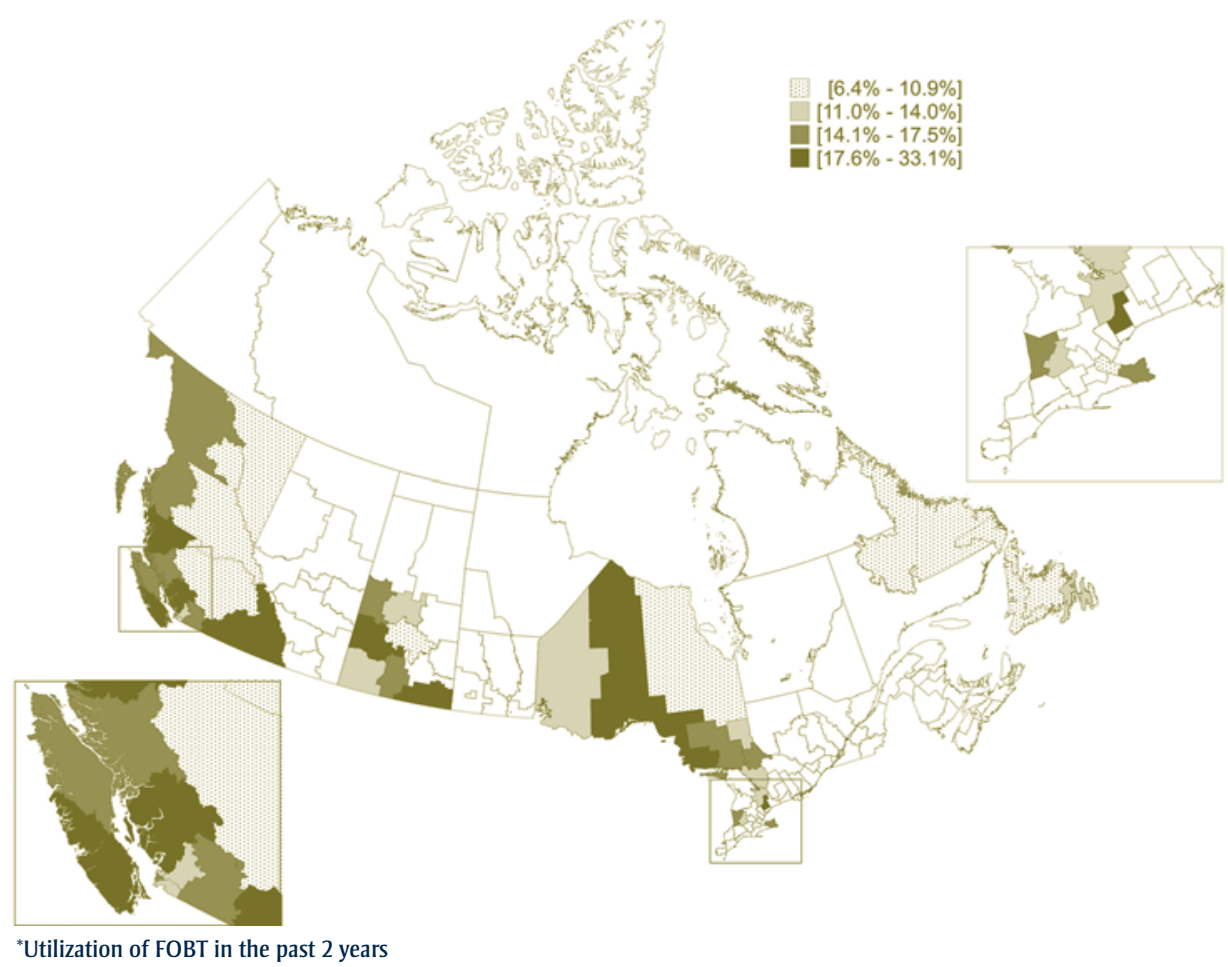


FIGURE 3

Health regional rates of never-use of FOBT

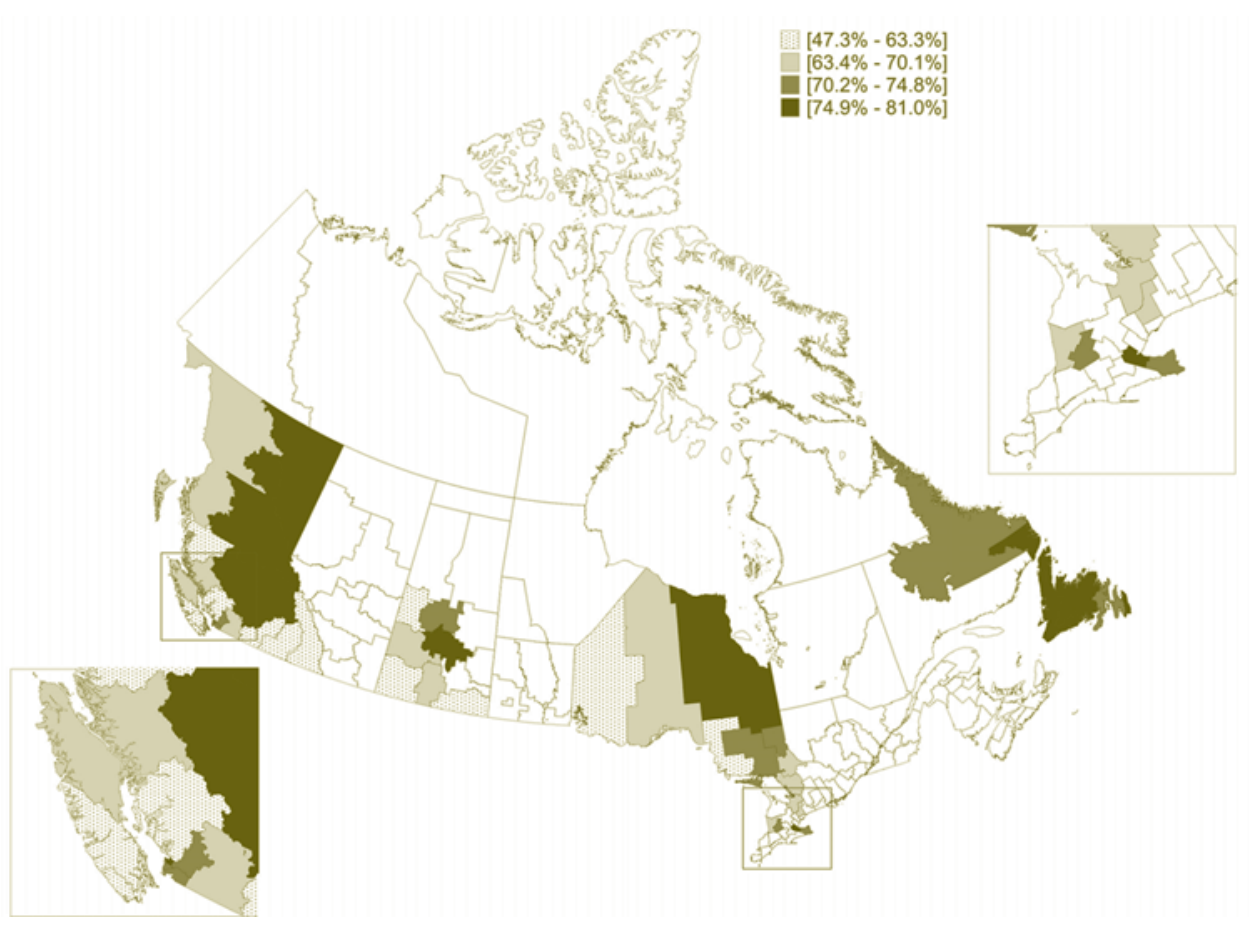

FIGURE 4

Health regional rates of adherence to endoscopy screening guidelines*

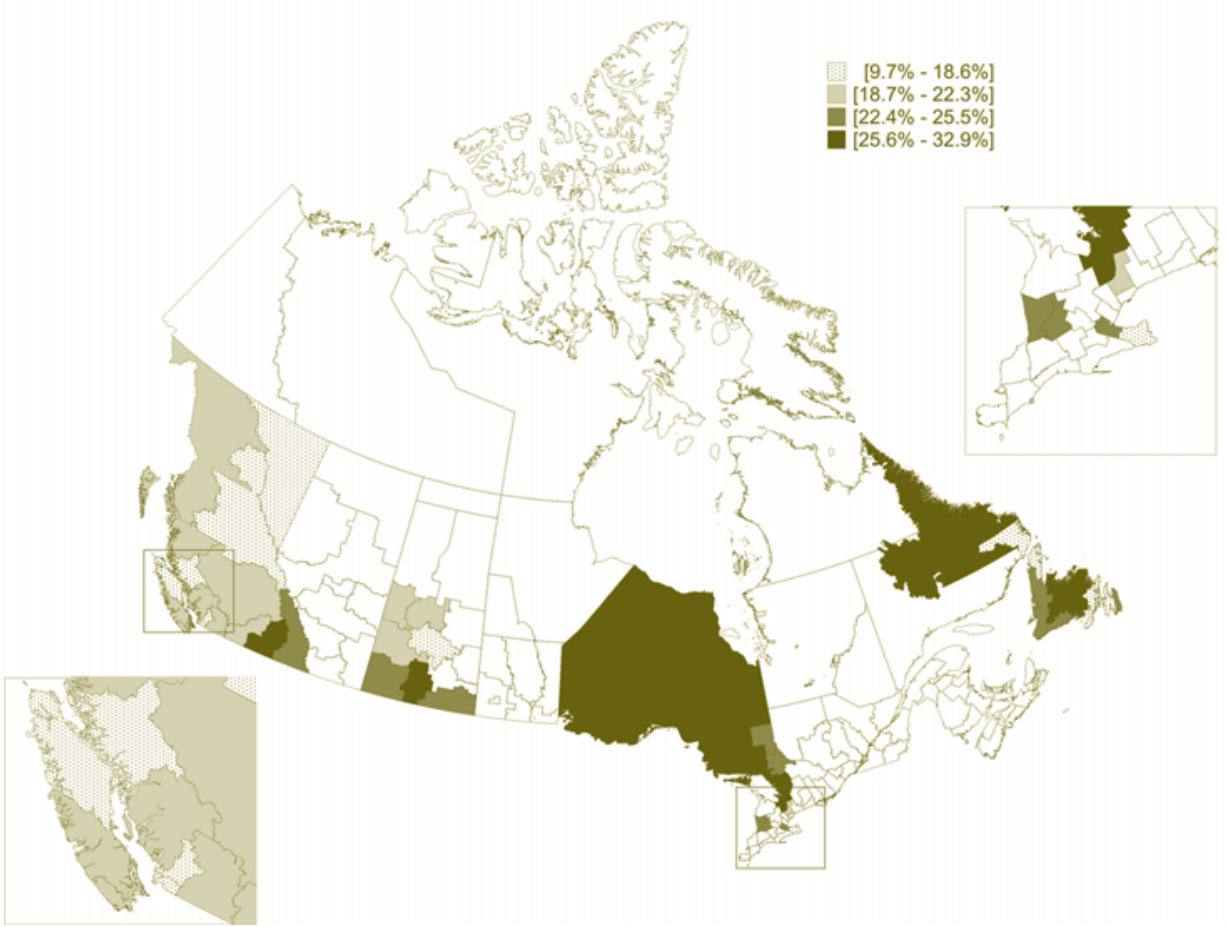

*Utilization of sigmoidoscopy or colonoscopy in the past 10 years 
FIGURE 5

Health regional rates of never-use of endoscopy

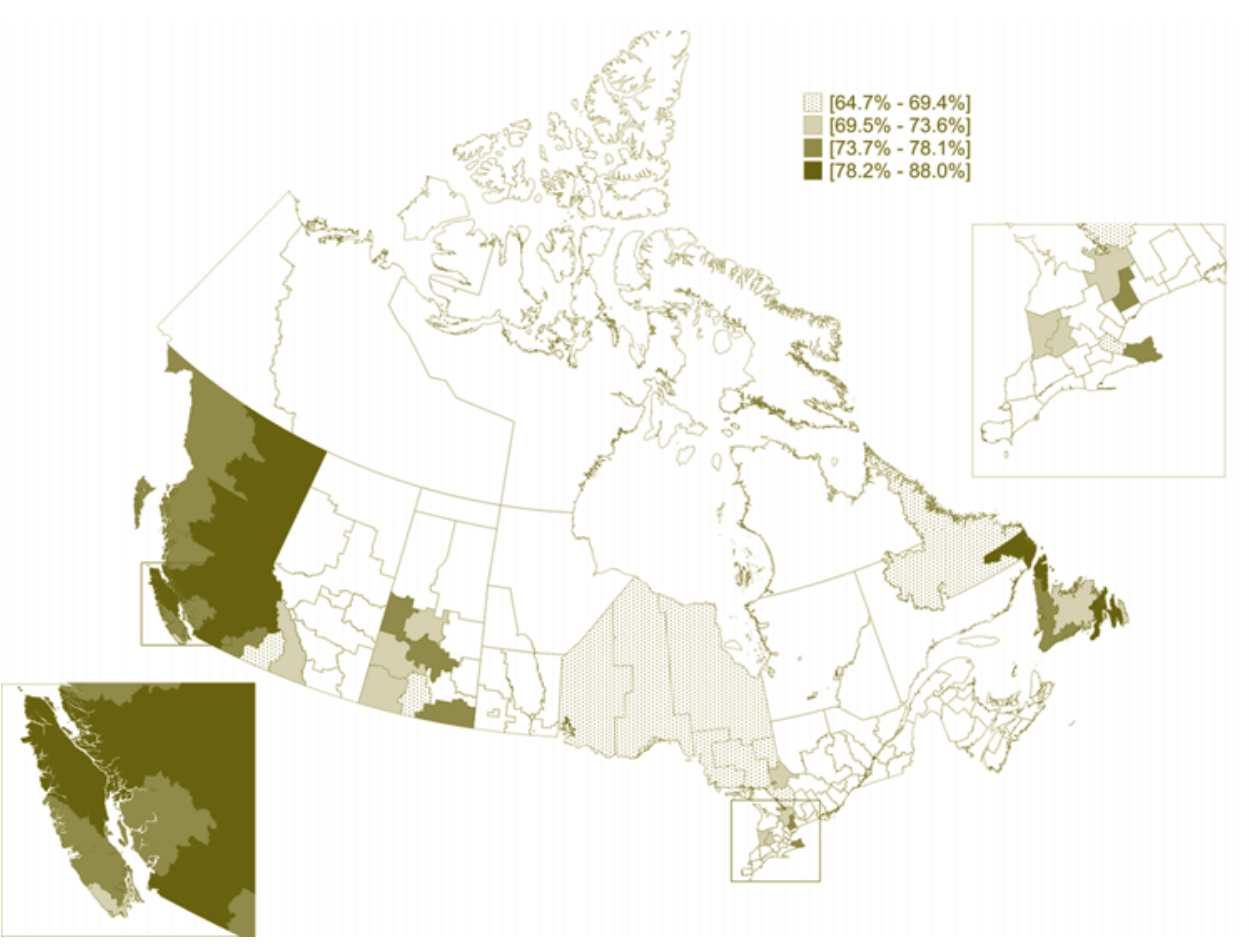

FIGURE 6

Health regional rates of non-adherence to current colorectal-cancer screening guidelines*

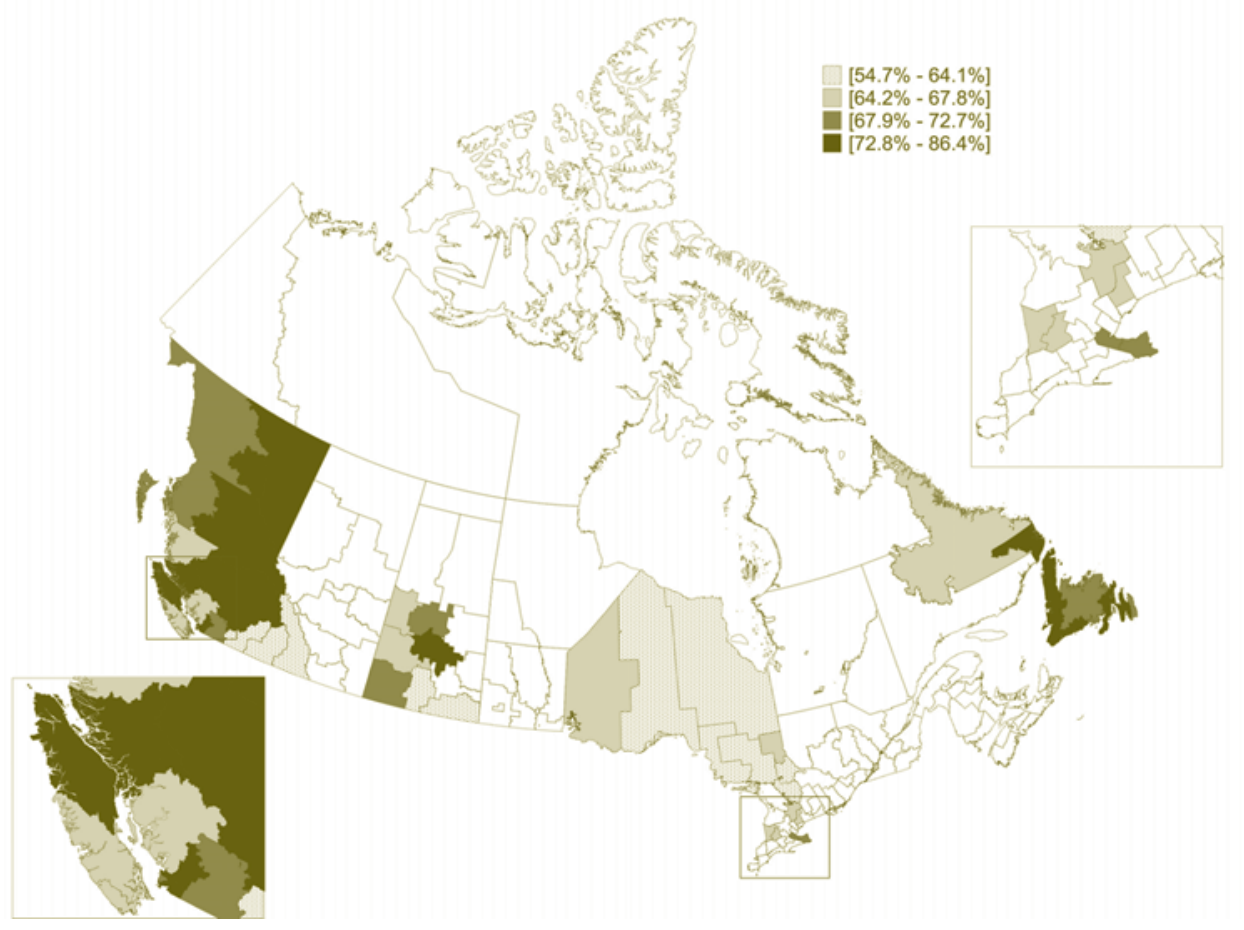

*Non-use of FOBT in the past 2 years and endoscopy in the past 10 years 
In Canada in 2003, $78.4 \%$ and $88.7 \%$ of respondents had never been screened by either FOBT or endoscopy, respectively. These findings mirror those of US population-based studies that found that up to $65 \%$ of individuals had never received either of these exams ${ }^{7,11,36}$ and of one Canadian study that reported that up to $77 \%$ had never been screened for CRC. ${ }^{14}$ Likewise, in a 6-year follow-up study of Ontario beneficiaries, nearly $80 \%$ of CRC screen-eligible individuals aged 50 to 59 years did not receive any large bowel evaluation. ${ }^{12}$ Not only do our findings point to the gross underuse of CRC screening, they also convey the message that CRC screening rates are considerably lower than those for either breast or cervical cancer. ${ }^{8,37,40}$ In 2003, the proportion of screen-eligible women who underwent guideline-recommended screening was $79 \%$ for Pap test and $61 \%$ for mammography, the latter increasing from $53 \%$ in $2001 .{ }^{25}$ The rise in breast-cancer screening rates may be explained by the increasing number of enrollees in provincially organized breast-cancer screening programs, which have been adopted by all Canadian provinces. ${ }^{41}$ Multimodal endeavors that proved effective for improving breastcancer screening rates may be effective at boosting rates of CRC screening. Undoubtedly, providing CRC screening within the context of an organized program may prove to be advantageous by promoting awareness of CRC screening, especially in the younger age group, and monitoring guideline-recommended CRC screening in average-risk Canadians.

Several limitations and strengths are important to consider when interpreting our findings. Endoscopy screening rates may have been overestimated if respondents with bowel disease indicated a screening procedure: since inflammatory bowel disease is a risk factor for the development of CRC, affected individuals are advised to undergo surveillance colonoscopy at more frequent time intervals compared to those considered at average-risk. However, this would not have meaningfully affected the rates of screening because less than $1 \%$ of the study population would have been misclassified $3.6 \%$ of respondents with bowel disease, of which $23 \%$ had a screening endoscopy in the past 5 years). Adherence to endoscopy screening guidelines may have been overestimated if individuals who underwent sigmoidoscopy beyond the recommended 5 years were included. Adherence to current CRC screening guidelines may have been underestimated as $1.3 \%$ of respondents were classified as non-adherent based on only one procedure. CRC screening rates may have been slightly underestimated as some of the 50-year-old respondents who reported not being screened at survey time may have been screened before the end of their $50^{\text {th }}$ year. Given the large variability by geographic location, results are likely not generalizable to Canadian provinces for which CRC screening data were not available.

Determining the extent to which CRC screening is performed nationally is methodologically challenging. Whereas administrative database studies cannot distinguish screening exams from those that are performed for other indications, surveys such as the CCHS Cycle 2.1 include responses that permit the determining of the indication for undergoing the procedure. In contrast, surveys that rely on self-report may be problematic for distinguishing sigmoidoscopy from colonoscopy. However, good sensitivity and specificity for selfreported use are found when the two procedures are grouped together, ${ }^{42,43}$ as was done in the CCHS.

Study strengths include 1) defining adherence to current CRC screening guidelines according to both FOBT and endoscopy, which provides a snapshot of the proportion of the population that has undergone CRC screening; and 2) determining outcomes in a population where over $96 \%$ are at average-risk for the development of CRC. Finally, rates by geographical location are likely to remain stable over short time intervals given that only $4.1 \%$ of Canadians aged 45 and over move out of province each year. ${ }^{44}$ Because this study used data from 2003 and awareness of CRC screening has increased substantially in the last few years, current CRC screening rates are likely higher than those reported.

\section{Conclusion}

In summary, most average-risk respondents had never been screened for CRC by either FOBT or endoscopy, with close to $70 \%$ being non-adherent to current screening guidelines. Higher rates of non-adherence to CRC screening guidelines in those aged 50 to 59 suggest delayed uptake of CRC screening recommendations by physicians and younger, average-risk Canadians. It is unclear why screening rates were lower in most regions of British Columbia. Greater use of endoscopy compared to FOBT suggests that it may be used increasingly as a primary CRC screening strategy. The absence of an urban vs. rural difference suggests that a lack of resources in rural areas is not impeding CRC screening. The very low screening rates found in this study coupled with the evidence that CRC screening can reduce incidence of and mortality from CRC suggest that multimodal efforts are needed to increase Canadians' awareness and use of CRC screening.

\section{Acknowledgments}

This research was supported by a grant from the Canadian Institutes for Health Research (CIHR), MOP 77666.

Maida J. Sewitch, $\mathrm{PhD}$, is supported as a Research Scientist of the Canadian Cancer Society through an award from the National Cancer Institute of Canada.

Ethical approval from the Research Ethics Board of the Research Institute of the McGill University Health Centre and permission from Statistics Canada were obtained prior to study inception.

\section{References}

1. Canadian Cancer Society/National Cancer Institute of Canada. Canadian Cancer Statistics, 2008. Toronto, 2008.

2. Public Health Agency of Canada. Reducing Canadian colorectal cancer mortality through screening. 2002. URL: http://www.phac-aspc. gc.ca/publicat/ncccs-cndcc/ccsrec-eng.php. 
3. Leddin D. The Canadian Association of Gastroenterology position on colon cancer screening. Can J Gastroenterol. 2003;17(2):133-134.

4. Canadian Cancer Society. Screening for colorectal cancer. 2004. URL: http://www. cancer.ca/ccs/internet/standard/0,3182, 3649_10175_74549480_langId-en,00.html.

5. U.S. Preventive Services Task Force. Screening for colorectal cancer: recommendations and rationale. Ann Intern Med. 2002;137(2):129-131.

6. Winawer S, Fletcher R, Rex D et al. Colorectal cancer screening and surveillance: clinical guidelines and rationaleupdate based on new evidence. Gastroenterology. 2003;124:544-560.

7. Ata A, Elzey JD, Insaf TZ, Grau AM, Stain SC, Ahmed NU. Colorectal cancer prevention: adherence patterns and correlates of tests done for screening purposes within United States populations. Cancer Detect Prev. 2006;30(2):134-143.

8. Increased use of colorectal cancer tests United States, 2002 and 2004. MMWR Morb Mortal Wkly Rep. 2006;55(11):308-311.

9. McGlynn EA, Asch SM, Adams J, et al. The quality of health care delivered to adults in the United States. $\mathrm{N}$ Engl J Med. 2003;348(26):2635-2645.

10. Etzioni DA, Ponce NA, Babey SH et al. A population-based study of colorectal cancer test use: results from the 2001 California Health Interview Survey. Cancer. 2004;101 (11):2523-2532.

11. McQueen A, Vernon SA, Meissner HI, Klabunde CN. Are there gender differences in colorectal cancer test use prevalence and correlates? Cancer Epidemiology, Biomarkers \& Prevention. 2006;15(4):782-791.

12. Rabeneck L, Paszat LF. A population-based estimate of the extent of colorectal cancer screening in Ontario. Am J Gastroenterol. 2004;99(6):1141-1144.
13. Vinden C, Schultz S, Rabeneck L. ICES Research Atlas: Use of Large Bowel Procedures in Ontario. Toronto, ON: Institute for Clinical Evaluative Sciences (ICES), 2004.

14. Ramji F, Cotterchio M, Manno M, Rabeneck L, Gallinger S. Association between subject factors and colorectal cancer screening participation in Ontario, Canada. Cancer Detection and Prevention. 2005;29(3):221-226.

15. McGregor SE, Hilsden RJ, Li FX, Bryant HE, Murray A. Low uptake of colorectal cancer screening 3 years after release of national recommendations for screening. Am J Gastroenterol. 2007;102(8):1727-1735.

16. Statistics Canada. Canadian Community Health Survey Cycle 2.1. 2003. URL:http:// www.statcan.ca/english/concepts/health/ cycle2_1/cchsinfo.htm.

17. Statistics Canada. The Canadian Community Health Survey, Cycle 2.1. 2002.

18. Statistics Canada. Health regions: Boundaries and correspondence with census geography. 2003. Catalogue no. 82-402-XIE.

19. Statistics Canada. Canadian Community Health Survey 2003: User Guide for the Public Use Microdata File of 2005:22-32.

20. SAS Version 8.02. Cary, North Carolina, USA, 2001.

21. Hilsden RJ. Patterns of use of flexible sigmoidoscopy, colonoscopy and gastroscopy: a population-based study in a Canadian province. Can J Gastroenterol. 2004;18(4):213-2119.

22. Ko CW, Kreuter W, Baldwin L-M. Persistent demographic differences in colorectal cancer screening utilization despite Medicare reimbursement. BMC Gastroenterol. 2005;5(1):10.

23. Cooper GS, Koroukian SM. Geographic variation among Medicare beneficiaries in the use of colorectal carcinoma screening procedures. Am J Gastroenterol. 2004;99(8):1544-1550.
24. Fehringer G, Howlett R, Cotterchio M, Klar N, Majpruz-Moat V, Mai V. Comparison of papanicolaou (Pap) test rates across Ontario and factors associated with cervical screening. Can J Public Health. 2005;96(2):140-144.

25. Canadian Cancer Society/National Cancer Institute of Canada. Canadian Cancer Statistics 2006.

26. Lemon S, Zapka J, Luckmann R, ChasanTaber L. Colorectal cancer screening participation: comparisons with mammography and prostate-specific antigen screening. Am J Pub Health. 2001;91(8): 1264-1272.

27. Cokkinides VE, Chao A, Smith RA, Vernon SW, Thun MJ. Correlates of underutilization of colorectal cancer screening among U.S. adults, age 50 years and older. Prev Med. 2003;36(1):85-91.

28. Nadel MR, Blackman DK, Shapiro JA, Seeff LC. Are people being screened for colorectal cancer as recommended? Results from the National Health Interview Survey. Prev Med. 2002;35(3):199-206.

29. Walsh JME, Posner SF, Perez-Stable J. Colon cancer screening in the ambulatory setting. Prev Med. 2002;35(3):209-218.

30. Thompson B, Coronado GD, Solomon CC, McClerran DF, Neuhouser ML, Feng Z. Cancer prevention behaviours and socioeconomic status among Hispanics and nonHispanic whites in a rural population in the United States. Cancer Causes and Control. 2002;13(8):719-728.

31. Brawarsky P, Brooks DR, Mucci LA. Correlates of colorectal cancer testing in Massachusetts men and women. Prev Med. 2003;36(6):659-668.

32. Ioannou GN, Chapko MK, Dominitz JA. Predictors of colorectal cancer screening participation in the United States. Am J Gastroenterol. 2003;98(9):2082-2091. 
33. Madlensky L, Esplen MJ, Gallinger S, McLaughlin JR, Goel V. Relatives of colorectal cancer patients. Factors associated with screening behavior. Am J Prev Med. 2003;25(3):187-194.

34. Harewood GC, Lieberman DA. Colonoscopy practice patterns since introduction of Medicare coverage for average-risk screening. Clin Gastroenterol Hepatol. 2004;2(1):72-77.

35. Flanagan WM, LePetit C, Berthelot JM, White KJ, Coombs BA, Jones-McLean E. Potential impact of population-based colorectal cancer screening in Canada. Chronic Dis Can. 2003;24(4):81-88.

36. Colorectal cancer test use among persons aged $>$ or $=50$ years - United States, 2001 . MMWR Morb Mortal Wkly Rep. 2003; 52(10):193-196.

37. Swan J, Breen N, Coates RJ, Rimer BK, Lee NC. Progress in cancer screening practices in the United States. Results from the 2000 National Health Interview Survey. Cancer. 2003;97(6):1528-1540.

38. Robertson RH, Burkhardt JH, Powell MP, Eloubeidi MA, Pisu M, Weissman NW. Trends in colon cancer screening procedures in the US Medicare and Tricare populations: 1999-2001. Prev Med 2006;42(6):460-462.

39. Meissnner HI, Breen N, Klabunde CN, Vernon SW. Patterns of colorectal cancer screening uptake among men and women in the United States. Cancer Epidemiology, Biomarkers \& Prevention 2006;15(2):389-394.

40. Miedema BB, Tatemichi S. Breast and cervical cancer screening for women between 50 and 69 years of age: what prompts women to screen? Womens Health Issues. 2003;13(5):180-184.

41. Wadden N, Doyle GP. Breast cancer screening in Canada: a review. Can Assoc Radiol J. 2005;56(5):271-275.
42. Baier M, Calonge N, Cutter G et al. Validity of self-reported colorectal cancer screening behavior. Cancer Epidemiology, Biomarkers \& Prevention. 2000;9(2):229-232.

43. Madlensky L, McLaughlin J, Goel V. A comparison of self-reported colorectal screening with medical records. Cancer Epidemiology, Biomarkers \& Prevention. 2003;12(7):656-659.

44. Statistics Canada. Population 1 year and over by age groups, showing mobility status (place of residence 1 year ago), for Canada, provinces and territories, 1996 census (20\% sample data). URL: http://www.statcan.ca/ english/census96/apr14/mob2.htm. 